\title{
Requalificação urbana em áreas contaminadas na cidade de São Paulo
}

MATEUS HABERMANN ${ }^{I}$ e NELSON GOUVEIA II

\section{Introdução}

A MAIORIA das regiões metropolitanas enfrenta problemas crescentes de expansão urbana, perda de vegetação natural e um declínio geral na extensão e conectividade de hábitats selvagens. Ao mesmo tempo, as áreas urbanas centrais passam por um esvaziamento nas últimas décadas. Em São Paulo, no começo do século XXI, apenas 46\% das indústrias operantes em 1980 nas regiões ao longo dos eixos ferroviários e rios principais ainda permaneciam ativas, aproximadamente $21 \%$ possuíam novos usos não industriais (Silva, 2002).

As causas são diversas, uma delas é o deslocamento das indústrias para o interior do estado ou outras regiões do país, o que gera espaços vazios, degradados, subutilizados ou abandonados, denominados brownfields (Günter, 2006; Morinaga et al., 2008; SVMA, 2012).

Dependendo do uso anterior, essas áreas podem apresentar contaminação do solo e água subterrânea. Área contaminada é aquela em que há comprovadamente poluição causada pela disposição inadequada de resíduos depositados, acumulados, armazenados, enterrados ou infiltrados, manejo inadequado de substâncias perigosas nos processos industriais em operação, armazenamento inadequado, vazamentos, acidentes, além da desativação de processos produtivos (Günter, 2006; Valentim, 2007).

Esse quadro resulta, portanto, em situações de risco ao meio ambiente e à saúde da população exposta aos contaminantes, e afeta a qualidade de vida urbana, principalmente se essas áreas forem reutilizadas sem medidas prévias de remediação ou confinamento do passivo ambiental.

A exposição se processa de modo lento e gradual, geralmente por longo período de tempo e a baixas doses de exposição a poluentes químicos perigosos. Os efeitos à saúde poderão surgir futuramente e incluem doenças crônico-degenerativas, distúrbios respiratórios, hepáticos, renais, cardiovasculares, reprodutivos e neurológicos, além do câncer, o qual pode surgir muito tempo depois da exposição (Günter, 2006).

O planejamento urbano em regiões com número significativo de áreas degradadas e/ou contaminadas necessita, portanto, levar em conta as caracterís- 
ticas ambientais dessas áreas e incorporar repertório e metodologias de avaliação de riscos à saúde. Ao mesmo tempo, as políticas ambientais e de saúde pública devem interpretar o ambiente urbano como elemento determinante e condicionante da qualidade de vida e bem-estar de seus habitantes, uma vez que essas áreas geralmente encontram-se dotadas com infraestrutura e serviços urbanos bem consolidados (Valentim, 2007), diminuindo a pressão para áreas periféricas de proteção ambiental, promovendo sustentabilidade.

Muitas vezes, a reincorporação de imóveis degradados ao tecido urbano ocorria de forma precipitada, inadequada e potencialmente perigosa, sem qualquer preocupação quanto à existência de uma possível contaminação do solo, dos aquíferos ou das instalações, se reaproveitadas.

Para inibir ações como essas foram tomadas iniciativas voltadas para a recuperação de áreas contaminadas e/ou deterioradas e nortear a gestão de reúso dessas áreas. A Companhia de Tecnologia de Saneamento Ambiental (Cetesb), ligada à Secretaria do Meio Ambiente, lançou o Manual de gerenciamento de áreas contaminadas (Cetesb, 2001), sobre metodologia de gerenciamento e encaminhamento de soluções à questão, do ponto de vista da recuperação ambiental; o Guia para avaliação do potencial de contaminação em imóveis (Cetesb, 2003), com precauções e procedimentos a serem adotados na aquisição de um imóvel ou no início do desenvolvimento de projeto de reutilização.

Além disso, há legislações específicas sobre o tema, como o Decreto Estadual n.47.400/2002, que estabelece a obrigatoriedade de comunicação ao órgão competente sobre o encerramento das atividades passíveis de licenciamento ambiental. Isso evita ocorrência de áreas órfãs, aquelas em que não é possível identificar os responsáveis pelo dano ambiental. No art. 201 da Lei Municipal n.13.885/2004 ficou estabelecido que a aprovação de projetos de parcelamento do solo, edificação, mudança de uso ou instalação de equipamentos considerados contaminados ou suspeitos de contaminação ficassem condicionados à apresentação pelo empreendedor, de laudo técnico de investigação do terreno a ser submetido à apreciação e deliberação do órgão ambiental competente.

Em vista da quantidade significativa dessas áreas no município de São Paulo e considerando, ainda, o uso e ocupação do solo adequado, o objetivo do estudo foi avaliar a densidade urbana, disponibilidade de infraestrutura de saneamento, assim como a situação socioeconômica da vizinhança dessas áreas para verificar seu potencial de reocupação e requalificação urbana.

\section{Métodos}

O estudo foi realizado no município de São Paulo, que possui população de 11.379 .114 habitantes, com uma área de $1.509 \mathrm{~km}^{2}$ e grau de urbanização de 99,1\% (Seade, 2013).

A Cetesb é o órgão estadual responsável pelo registro e o armazenamento dos dados obtidos sobre áreas contaminadas, em processo de monitoramento 
para reabilitação, ou reabilitadas. Para esse estudo foi utilizado o cadastro do ano 2010 e selecionados os imóveis localizados no município de São Paulo.

Foram utilizadas informações do Censo 2010 do IBGE, contidas na base de setores censitários, com informações do número de domicílios particulares permanentes, número de chefes de domicílios particulares permanentes, domićlios particulares permanentes ligados à rede geral de esgoto, rendimento nominal médio mensal. Ao trabalhar com as informações agregadas por setores censitários, acredita-se avaliar a situação socioeconômica da população, bem como as infraestruturas urbanas dos quais essa população é suprida em seus domicílios.

Utilizando o programa MapInfo (Professional version 8.5: MapInfo Corporation, New York, NY, USA), os endereços das áreas contaminadas foram geocodificados. Com a base cartográfica de setores censitários foi identificado quantas áreas contaminadas estavam contidas em cada setor do município de São Paulo. Esses setores foram dicotomizados entre os que não possuíam áreas contaminadas e aqueles com 01 e mais áreas.

Os indicadores desse estudo incluíram densidade de domicílios (domicílios $/ \mathrm{km}^{2}$ ), rendimento médio dos responsáveis por domicílios de cada setor censitário, percentual de domicílios ligados à rede geral de esgoto, percentual de domicílios com coleta de resíduos sólidos, e percentual de domicílios com dez e mais moradores.

As diferenças das médias e quartis (mediana e percentis 25 e 75 ) dos indicadores selecionados foram comparados entre os setores com 01 e mais áreas e sem áreas contaminadas. Uma vez que não houve amostragem esses indicadores puderam ser comparados sem aplicação de testes estatísticos.

\section{Resultados}

Em 2010 a cidade de São Paulo contava com 1.190 áreas registradas no cadastro da Cetesb, a maior parte delas classificada como contaminada, representando quase $76,2 \%$ do total. As áreas em monitoramento para reabilitação e reabilitadas, somadas, representaram $23,8 \%$, conforme se observa na Tabela 1.

Conforme se verifica na Figura 1, o uso do solo potencialmente poluidor (industrial/armazéns) concentra-se basicamente ao longo dos eixos ferroviários e dos rios principais - Tietê, Pinheiros e Tamanduateí, em bairros como Mooca, Vila Leopoldina, Barra Funda e Santo Amaro. As áreas que apresentam contaminação encontram-se dispersas pelo tecido urbano, com maior concentração nas áreas centrais. São caracterizadas por imóveis isolados, como postos de abastecimento de combustíveis.

As áreas contaminadas estavam contidas em 969 setores censitários, o que representou $5,1 \%$ dos 18.953 setores da cidade. Na maior parte havia uma área contaminada $(4,4 \%)$ e aqueles setores com duas ou mais áreas representaram $0,7 \%$ do total (dados não mostrados). 


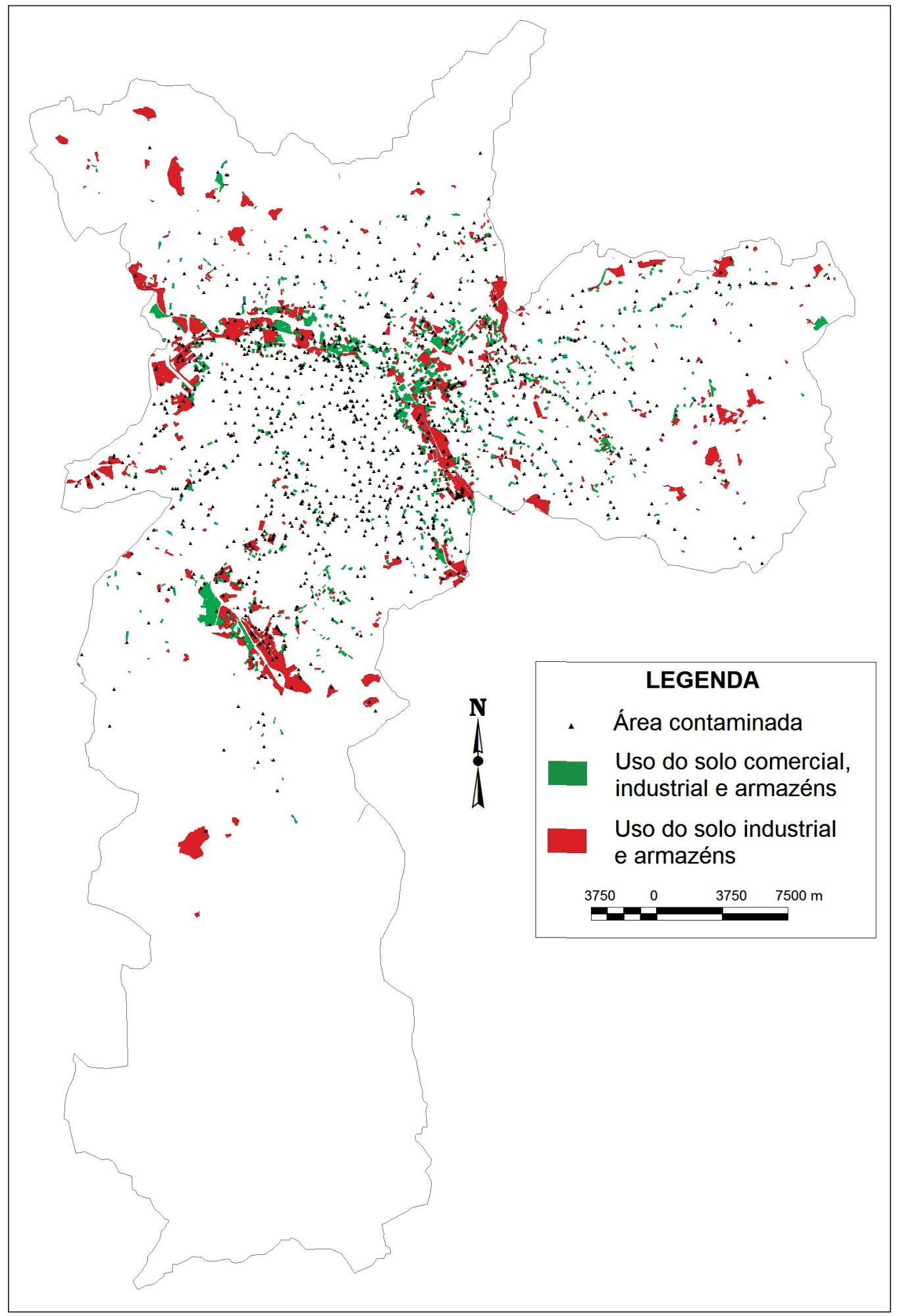

Figura 1 - Áreas contaminadas e usos do solo potencialmente contaminadores do solo e água subterrânea (industrial/armazéns). Município de São Paulo, 2010 . 
Tabela 1 - Situação das áreas classificadas pela Cetesb como contaminadas na cidade de São Paulo, 2010

\begin{tabular}{l|c}
\hline Situação & Áreas (\%) \\
\hline Contaminada & $557(46,8 \%)$ \\
\hline Contaminada sob investigação & $350(29,4 \%)$ \\
\hline Em processo de monitoramento para reabilitação & $214(18,0 \%)$ \\
\hline Reabilitada & $69(5,8 \%)$ \\
\hline Total & $1.190(100 \%)$ \\
\hline
\end{tabular}

$\mathrm{Na}$ análise dos valores de média e quartis dos indicadores sociodemográficos e de saneamento é possível observar que os setores com áreas contaminadas possuem menor densidade domiciliar e rendimento médio mensal mais alto. Os setores com áreas contaminadas também apresentam maior percentual de domicílios com acesso a rede geral de esgoto e coleta de resíduos sólidos, comparados aos setores sem área contaminada. Além disso, o percentual médio de domicílios com dez e mais moradores é menor nos setores com área contaminada (Tabela 2).

Tabela 2 - Média e quartis das indicadores sociodemográficos e de saneamento dos setores censitários com e sem área contaminada, na cidade de São Paulo, 2010

\begin{tabular}{|c|c|c|c|c|c|}
\hline Variável & $\begin{array}{l}\text { Situação do setor } \\
\text { censitário }\end{array}$ & Média & $2^{\circ}$ quartil & $\begin{array}{l}3^{\circ} \text { quartil } \\
\text { (mediana) }\end{array}$ & $4^{\circ}$ quartil \\
\hline $\begin{array}{l}\text { Densidade domiciliar } \\
\left(\text { em domicílio/ } \mathrm{km}^{2}\right)\end{array}$ & $\begin{array}{l}\text { Sem área contaminada } \\
\geq 1 \text { área contaminada }\end{array}$ & $\begin{array}{l}11.918 \\
4.203\end{array}$ & $\begin{array}{l}3.319 \\
1.419\end{array}$ & $\begin{array}{l}5.403 \\
2.891\end{array}$ & $\begin{array}{l}9.372 \\
4.728\end{array}$ \\
\hline $\begin{array}{l}\text { Rendimento médio } \\
\text { mensal (em } \mathrm{R} \$ \text { ) }\end{array}$ & $\begin{array}{l}\text { Sem área contaminada } \\
\geq 1 \text { área contaminada }\end{array}$ & $\begin{array}{l}1.324,97 \\
2.019,24\end{array}$ & $\begin{array}{l}517,41 \\
965,20\end{array}$ & $\begin{array}{l}763,26 \\
1.422,64\end{array}$ & $\begin{array}{l}1.486,68 \\
2.512,10\end{array}$ \\
\hline $\begin{array}{l}\text { Ligação à rede geral } \\
\text { de esgoto (\%) }\end{array}$ & $\begin{array}{l}\text { Sem área contaminada } \\
\geq 1 \text { área contaminada }\end{array}$ & $\begin{array}{l}89,4 \% \\
97,4 \%\end{array}$ & $\begin{array}{l}99,3 \% \\
98,9 \%\end{array}$ & $\begin{array}{l}99,6 \% \\
100 \%\end{array}$ & $\begin{array}{l}100 \% \\
100 \%\end{array}$ \\
\hline $\begin{array}{l}\text { Coleta de resíduos } \\
\text { sólidos (em \%) }\end{array}$ & $\begin{array}{l}\text { Sem área contaminada } \\
\geq 1 \text { área contaminada }\end{array}$ & $\begin{array}{l}98,8 \% \\
99,8 \%\end{array}$ & $\begin{array}{l}100 \% \\
100 \%\end{array}$ & $\begin{array}{l}100 \% \\
100 \%\end{array}$ & $\begin{array}{l}100 \% \\
100 \%\end{array}$ \\
\hline $\begin{array}{l}\geq 10 \text { moradores por } \\
\text { domicílio (em \%) }\end{array}$ & $\begin{array}{l}\text { Sem área contaminada } \\
\geq 1 \text { área contaminada }\end{array}$ & $\begin{array}{l}0,67 \% \\
0,48 \%\end{array}$ & $\begin{array}{l}0 \% \\
0 \%\end{array}$ & $\begin{array}{l}0 \% \\
0 \%\end{array}$ & $\begin{array}{l}1 \% \\
1 \%\end{array}$ \\
\hline
\end{tabular}

\section{Discussão}

Nesse estudo foi observado que os setores com área contaminada possuem mais infraestrutura urbana, pois têm percentual maior de domicílios com ligação à rede de esgoto e resíduos sólidos coletados. Apesar disso, esses possuem menor densidade de domicílios particulares permanentes por área, o que aponta um potencial de adensamento dessas vizinhanças. 
Além disso, os resultados encontrados para a cidade de São Paulo indicam que setores censitários com áreas contaminadas possuem população de rendimento mais elevado. A formação da ocupação da cidade de São Paulo leva a esse resultado, pois a área central e seu entorno imediato, com maior número de áreas contaminadas, concentra grande parte das infraestruturas de comércio, lazer, e, assim, dos locais de trabalho, tendendo a ser mais valorizada e habitada por pessoas de maior poder aquisitivo.

Esse resultado é o oposto ao verificado nos Estados Unidos, onde, em fins da década de 1970, cidadãos de baixa renda perceberam que residiam próximos de aterros de dejetos perigosos. Os movimentos originados dessas constatações ficaram conhecidos como Justiça Ambiental (Herculano, 2002), que destaca o déficit de responsabilidade do Estado e os mecanismos e processos decisórios que impõem riscos aos mais desprotegidos (pobres e minorias), tais como decisões sobre a localização de equipamentos que utilizam tecnologia danosa ao meio ambiente e à saúde etc. (Acselrad et al. 2004).

$\mathrm{Na}$ realidade, os resultados desse estudo indicam a ocorrência do chamado "efeito bumerangue", no qual o esquema de classes sociais deixa de ser importante na distribuição das destruições e ameaças ao meio ambiente, e aqueles que mais se beneficiam com os produtos e serviços geradores de riscos também estão vulneráveis diante desses (Beck, 2010), inclusive aqueles riscos oriundos da contaminação do solo e água subterrânea.

Embora os mais ricos residam nas regiões com mais áreas contaminadas, isso não necessariamente implica maior exposição e impactos à saúde. Deve-se salientar que o registro da Cetesb não engloba todas as áreas contaminadas, uma vez que muitos imóveis podem estar contaminados sem que essa contaminação tenha sido detectada. No caso das áreas contaminadas situadas na periferia, onde não há interesse do mercado imobiliário, entende-se que o poder público pode atuar como indutor do processo de recuperação (Morinaga et al. 2008).

As áreas degradadas e contaminadas têm seu reúso prejudicado pela limitada demanda de mercado, inclusive porque a reutilização de qualquer área contaminada depende de ações de remediação ambiental (Leite; Cortez, 2006). Nesse sentido, a aplicação de incentivos fiscais é uma alternativa importante para promover a ocupação das áreas degradadas; no entanto, é importante que esse incentivo não seja pequeno a ponto de não ser atrativo, e grande a ponto de gerar privilégios privados.

O Estatuto da Cidade (Lei Federal n.10.527/2001) representou um avanço e fortaleceu o poder do município na gestão ambiental, na medida em que orienta o desenvolvimento das funções sociais da cidade por meio de planejamento, ordenação e controle do uso do solo, possibilidade de utilização de instrumentos urbanísticos; por exemplo, para os casos de áreas contaminadas, quando o proprietário atual não foi o poluidor, é admissível permitir a isenção parcial ou total dos valores previstos para adquirir concessão adicional de 
construção previsto na outorga onerosa do direito de construir, mediante remediação da área e, também, as operações urbanas, idealizadas para promover intervenções de requalificação em áreas com disfunções urbanas por meio de parcerias público-privadas, com incentivo à remediação (Morinaga et al. 2008).

$\mathrm{Na}$ sua atual condição, as áreas degradadas e/ou contaminadas provocam descontinuidades urbanas, contribuindo para a desvalorização, não somente da área onde se localiza, mas também de seu entorno (Leite; Cortez, 2006). Os espaços vazios associados à ação do tempo proporcionam um impacto visual negativo do ponto de vista urbanístico, que podem servir de abrigo a usuários de drogas e promover delinquência.

O dinamismo econômico e imobiliário potencializa o crescimento da mancha urbana nas periferias e consequente degradação de áreas de mananciais e/ou proteção permanente. Tal ocupação traz esgoto doméstico, lixo e carga urbana difusa de poluição, levando ao comprometimento da qualidade da água bruta e à possível inviabilização de uso do manancial, tão importantes para garantia do abastecimento de água nas áreas urbanas (Silva; Porto, 2003). Ao mesmo tempo, a elevada concentração de terrenos contaminados ao longo das áreas de várzeas, como se verificou nesse estudo nos rios Tamanduateí, Tietê e Pinheiros, compromete ainda mais a poluição desses corpos hídricos, o que reforça a execução de medidas de remediação dos imóveis contaminados.

Além disso, a recuperação e a refuncionalização dessas áreas mais próximas aos centros comerciais e aos eixos de desenvolvimento da cidade contribuem para o controle do desperdício de espaços urbanos, essencial para a conquista de um ambiente urbano sustentável. Os deslocamentos pendulares da população de suas casas ao local de trabalho/estudo são diminuídos, gerando menos congestionamentos e, consequentemente, menos poluição atmosférica gerada pelo elevado fluxo veicular.

Por fim, em vista da menor densidade domiciliar dessas áreas, enfatiza-se a necessidade de políticas públicas efetivas de gestão integrada entre meio ambiente e de uso e ocupação do solo no que se refere à requalificação de imóveis degradados, em particular das áreas contaminadas, privilegiando ações direcionadas à remediação que eliminem os riscos à saúde dos trabalhadores de obras e seus futuros ocupantes.

\section{Referências}

ACSELRAD, H.; HERCULANO, S.; PADUA, J. A. Justiça ambiental e a cidadania. Rio de Janeiro: Relume Dumará, 2004.

BECK, U. Sociedade de risco: rumo a uma nova modernidade. São Paulo: Ed. 34, 2010. BRASIL. Lei n.10.527, de 10 de julho de 2001. Diário Oficial da União, Seção 1 Atos Poder Legislativo, edição n.133 de 11.7.2001. 
COMPANHIA DE TECNOLOGIA DE SANEAMENTO AMBIENTAL - CETESB. Manual de gerenciamento de áreas contaminadas. São Paulo: Cetesb, 2001.

. Guia para avaliação do potencial de contaminação em imóveis. São Paulo: Cetesb, 2003.

GÜNTER, M. R. W. Áreas contaminadas no contexto da gestão urbana. São Paulo em Perspectiva, v.20, n.2, p.105-17, 2006.

HERCULANO, S. Riscos e desigualdade social: a temática da Justiça Ambiental e sua construção no Brasil [internet]. In: I ENCONTRO DA ANPPAS. Indaiatuba, 2002. Disponível em: <http://www.anppas.org.br/encontro_anual/encontrol/gt/teoria_ meio_ambiente/Selene\%20Herculano.pdf>: Acesso em: abril 2013.

LEITE, T. M. C.; CORTEZ, A. T. C. Entraves espaciais: brownfields caracterizados por aterros de resíduos sólidos urbanos desativados no município de São Paulo/SP. In: GERARDI, L. H. O.; CARVALHO, P. F. (Org.) Geografia: ações e reflexões. Rio Claro: Ageteo, 2006. p.151-62.

MORINAGA, C. M. et al. As potencialidades e limitações da aplicação de instrumentos urbanísticos de incentivo para a revitalização de áreas contaminadas na cidade de São Paulo. In: MOERI, E. N.; RODRIGUES, D.; NIETERS, A. (Ed.) Áreas contaminadas, remediação e revitalização: estudos de caso nacionais e internacionais. São Paulo: Instituto Ekos Brasil/GTZ, 2008. v.4.

SÃO PAULO (Estado). Decreto n.47.700, de 5 de dezembro de 2002. Diário Oficial do Estado, Executivo, São Paulo, p.10.

SÃO PAULO (Município). Lei n.13.885, de 25 de agosto de 2004. Diário Oficial do Município de São Paulo, São Paulo, p.1, suplemento 687.

SEADE (Fundação). Perfil municipal. Disponível em <www.seade.sp.gov.br>. Acesso em: abril 2013.

SECRETARIA DO VERDE E DO MEIO AMBIENTE DA CIDADE DE SÃO PAULO (SVMA). Manual: promovendo a comunicação e a participação social e institucional no planejamento urbano. São Paulo: SVMA, 2012.

SILVA, A. C. M. A. A importância dos fatores ambientais na reutilização de imóveis industriais em São Paulo. 2002. Dissertação (Mestrado) - Escola Politécnica, Universidade de São Paulo. São Paulo, 2002.

SILVA, R. T.; PORTO, M. F. A. Gestão urbana e gestão das águas: caminhos da integração. Estudos Avançados, v.17, n.47, p.129-45, 2003.

VALENTIM, L. S. O. Requalificação urbana, contaminação do solo e riscos à saúde. São Paulo: Annablume; Fapesp, 2007.

RESUMO - Áreas metropolitanas enfrentam problemas crescentes de expansão urbana. Ao mesmo tempo, imóveis de regiões centrais passam por um esvaziamento e, dependendo do uso anterior, podem apresentar contaminação do solo e água subterrânea. $\mathrm{O}$ objetivo deste artigo é, assim, avaliar a densidade urbana, disponibilidade de infraestrutura de saneamento e situação socioeconômica da vizinhança para verificar o potencial de reocupação e requalificação urbana de áreas contaminadas na cidade de São Paulo. Por meio de SIG, o cadastro 2010 da Cetesb com os endereços das áreas contaminadas 
foi georreferenciado e os setores censitários com informações do Censo/2010 como densidade domiciliar, acesso a rede geral de esgoto, coleta de lixo e rendimento foram dicotomizados entre aqueles com e sem áreas contaminadas, sendo analisadas as diferenças de média e quartis dessas variáveis. A cidade contava com 1.190 áreas cadastradas como contaminadas, distribuídas em $5,1 \%$ dos seus setores censitários. Setores com áreas contaminadas possuem menor densidade domiciliar e maior acesso a rede geral de esgoto, coleta de resíduos sólidos e rendimento comparados aos setores sem área contaminada. Setores censitários com áreas contaminadas possuem maior infraestrutura de saneamento; no entanto, possuem menor densidade de domicílios. Apesar do esforço de reocupação dessas áreas, nota-se ainda um grande potencial de crescimento dessas regiões na cidade.

PALAVRAS-CHAVE: Poluentes do solo, Planejamento de cidades, Reforma urbana, Poluentes da água, Controle da contaminação ambiental.

ABSTRACT - Metropolitan areas face increasing problems of urban sprawl. Simultaneously suffer an emptying of properties and depending on the prior use, may exhibit contamination of soil and ground water. The article aims to evaluate the urban density, availability of sanitation infrastructure and socioeconomic status of the neighborhood to check the potential for urban redevelopment and reoccupation of contaminated areas in the city of São Paulo. Through GIS the Cetesb database for the year 2010 with the addresses of the contaminated areas was georeferenced and census tracts with information Censo/2010 as household density, access the sewage system, garbage collection, and income were dichotomized between those with and no contaminated areas. The differences between of median and quartiles of these variables were compared. The city had 1,190 registered as contaminated areas, distributed in $5.1 \%$ of its census tracts. Census tracts with contaminated areas have lower household density and greater access to the sewage system, solid waste collection and performance compared to sectors without contaminated area. The census tract with contaminated areas have higher sanitation infrastructure, however, have a lower density of households. Despite the effort to reoccupy these areas, there is still great potential for growth in these areas in the city.

KEYWORDS: Soil pollutants, City planning, Urban renewal, Water pollutants, Environmental contamination control, Water contamination control, Soil contamination control.

Mateus Habermann é pesquisador de pós-doutorado na Chalmers University of Technology - Gotemburgo (Suécia). Doutor e mestre pelo Programa de Pós-Graduação em Ciências do Departamento de Medicina Preventiva da Faculdade de Medicina da Universidade de São Paulo, FMUSP. @ - mathab@usp.br

Nelson Gouveia é professor associado do Departamento de Medicina Preventiva, Faculdade de Medicina, Universidade de São Paulo, FMUSP. Doutor e mestre em Saúde Pública pela London School of Hygiene and Tropical Medicine, University of London. @-ngouveia@usp.br

Recebido em 19.4.2013 e aprovado em 9.1.2014.

I Chalmers University of Technology, Gotemburgo, Suécia.

II Faculdade de Medicina, Universidade de São Paulo, São Paulo/SP, Brasil. 
